\section{ASTHENOPIA NOT DUE TO REFRACTIVE} ERRORS. Read st the Meeting of the Chicago Ophthalmological and Otological
Society. Jau. 12, 1897.

BY HENRY GRADLE, M.D. CHICAGO,

The inability to use apparently healthy eyes for near work, without increasing discomfort or pain, is usually caused by refractive errors, or insufficiency of accommodation. In a series of 500 patients with asthenopic complaints taken consecutively from my records, the symptoms were caused by hypermetropia, astigmatism or presbyopia in 75 to 80 per cent. In 20 to 25 per cent. the asthenopia could not be accounted for in this manner, for either the optic conditions were perfect or, if not, their correction gave no relief.

Some of the factors which lead to asthenopia, in the instances not dependent upon optic faults, are suggested by a study of the refractive cases, if we consider them as patients and not merely as the possessors of optically imperfect eyes.

The importance of refractive errors varies according to whether we study them either in the patients of our office practice or in the population at large, that is to say, in school and military examinations, or in people whom we treat for other than refractive anomalies. Instructive, too, is the study of presbyopes. From such material it can be learned that many people can pass through life up to middle age without being annoyed by an existing hypermetropia or astigmatism of 1 , or perhaps even 1.5 dioptrics, and that when the error exceeds this amount, or the accommodation begins to decline with age, the normal and typical annoyance upon using the eyes is a feeling of strain or fatigue bordering on pain. In office practice, on the other hand, we see patients annoyed by errors far below this limit and complaining often, not merely of fatigue, but of various forms of pain. headache and even distant nervous symptoms. In a previous discussion of this subject ("The Neurological Aspect of Asthenopia," New York Medical Recond, Dec. 7, 1895) I have tried to emphasize these differences, by terming normal asthenopia that amount of fatigue and discomfort which is inevitably produced by a refractive error of sufficient degree, while I called exaggerated asthenopia the excessive eye annoyance which asthenopia leads to only in certain patients.

Observation shows that on the whole, those persons who complain only of normal asthenopia or who tolerate low errors without disturbance, represent the healthier part of the community. On the other hand, persons who suffer great annoyance in consequence of an unproportionately low degree of asthenopia, show often in many other ways that their nervous system is not in perfect condition. In some we get a decided history of inherited nervous instability. In others the past history, or perhaps only the subsequent observation, reveals other functional neuroses. Sometimes enfeebling infectious diseases have undermined the resisting power. Anemia or impaired digestion are also not uncommon precedents in exaggerated asthenopia. Finally faulty habits, improper hygiene, and especially insufficient muscular work, are very often factors which lead to an excessive reaction from eyestrain. The rôle of these various pernicious influ. ences is all the more striking in those instances in which a moderate refractive error had been borne without inconvenience until a breakdown occurs on account of such additional factors, while when these influences can be eliminated the patient may again be able to dispense with his correcting glasses. It is true there are cases, too, in which we can not elicit any other reason why a low error should cause such disproportionate discomfort, or why the eye strain should lead to other nervous symptoms. But is it not most logieal to admit that there must be some reason why that patient's nervous system reacts so much more than that of average healthy persons, even if we can not detect it? In other words, I hold that normal asthenopia is the natural discomfort associated with a refractive anomaly, while the man with exaggerated asthenopia is indeed a patient who has, beside his optic defect, a deficient nervous system. It is, however, self-evident that no sharp line can be drawn between normal and exaggerated asthenopia.

The same reasoning holds good for asthenopia dependent upon other causes beside optic defects. In about 3 per cent. of asthenopic patients $I$ find the ocular anomaly to be slight chronic inflammation of the conjunctiva or the edge of the lid. It is self-evident that a patient with pronounced conjunctivitis can not use his eyes without increasing discomfort, and it would be illogical and superfluous to describe his condition as asthenopia. If, however, decided asthenopic symptoms are complained of and we find merely a squumous blepharitis, or a minimal degree of chronic conjunctivitis so slight as to escape any but expert observation, and furthermore, if the annoy. ance ceases after the cure of the inflammatory condition, we can not but call it a case of exaggerated asthenopia. That is to say, the individual, on account of some peculiarity of his nervous system, reacts with asthenopia to an irritation which most persons can tolerate with scarcely any discomfort.

The symptoms of asthenopia dependent upon conjunctival irritation differ in many instances from the characteristic fatigue and ache due to ametropia. The annoyance is usually described as burning or watering, which may lead to headache in neurotic persons.

Occasionally asthenopia has a multiple origin. It may depend upon low ametropia in conjunction with blepharitis or chronic conjunctivitis and will in such instances require attention to both factors.

As another ocular lesion which bears some relation to asthenopia, I wish to refer to a certain anomaly of the retinal pigment epithelium. I do so with $\operatorname{some}$ reserve because I probably stand isolated in the interpretation and because the interpretation of such clinical facts is extremely difficult or uncertain. I refer now to certain slight changes in the appearance of the fundus which I have often met with in cases of exaggerated asthenopia. I can not give exact statistics because I have only paid attention to the subject in the last five years, while the statistics I quoted were partly from the time previously and partly from my records of last year. I should say, however, that I have observed this condition at least fifty to seventyfive times.

The normal fundus is, as you know, homogeneous in appearance. In some subjects, however, we find a condition which may be described as graining, or salt and pepper appearance. With it there may be in addition partial atrophy of the pigment epithelium exposing the choroidal vessels. The special lesion to which I refer seems to depend upon irregular distribution of the pigment epithelium, and we see an appearance which would be produced by the mixing 
of fine black and white powders with grains so minute that the eye can not discern the separate grains. Sometimes a few of the grains are coarse and discernible and white and black specks may be recognized with the ophthalmoscope. This condition is clearly more than a structural peculiarity. I judge so for the reason that when $I$ encountered it in adults it was in connection with actual lesions of the fundus as, for instance, in conjunction with localized foci of choroiditis and particularly during the retrogressive stage of neuritis. Otherwise I have hardly met with it in people over 25 years of age, but only in children and young people. This appearance is usually most pronounced in the lower nasal quadrant of the retina, but it may extend over the entire periphery and may even reach the macular area. I know of no reference to it in literature except the occasional use by writers of the term "woolly fundus," or "strippling." (Archives of Ophthalmology.) It is not identical with Gould's ametropic choroiditis.

With few exceptions the children in whom I found this appearance of the fundus were asthenopic. In some instances the asthenopia depended entirely upon refractive errors and was corrected definitely and permanently by glasses, but even in those cases it was always the exaggerated form of asthenopia. There was great complaint in proportion to the degree of error actually found. In other instances, however, there was no refractive error measurable, or if present its correction gave no benefit. These individuals were markedly neurotic and the neurasthenic condition might be taken to account as a predisposing cause for the asthenopia, but still the coincidence of this peculiar irregular distribution of the pigment epithelium in connection with such exaggerated asthenopic complaints is worthy of note and I would like to call the attention of the members to it. $\mathrm{We}$ can not influence the fundus condition directly by treatment, and hence can not prove absolutely its significance. It was generally accompanied in my cases by slightly lowered vision, about two-thirds or one-half, which could not be fully raised by glasses. It never led to any greater disturbance of vision, but it gave, in many cases, marked discomfort in the form of burning or smarting, often leading to headaches. There was commonly some sensitiveness to light, and the symptoms were most marked in the morning on rising. Although it was asthenopia in the sense that the discomfort increased on using the eyes, still the discomfort was ordinarily not quite absent and generally most pronounced on rising.

The only therapeutic measures that gave me any satisfaction whatsoever were absolute rest of the eyes and dark glasses. Personally, I have seen very little benefit from the dark glasses in other forms of asthenopia. But in this form the use of dark glasses has proven the most satisfactory of any of the measures employed.

This finishes all I can say about ocular causes of asthenopia, except that I might refer to the subject of muscular anomalies. That subject I trust, however, will be taken up by other members this evening who have had more experience than I have, for I have not seen much to convince me of the importance of muscular anomalies as a cause of asthenopia. My own impression has been that the number of cases in which muscular anomalies are associated with asthenopia is not large, if we analyze the cases properly, and that in the majority of instances the muscular anomalies are not dependent upon anatomic peculiarities of the muscles, but are of neurotic origin, rather associated with the asthenopia than the cause of it. However, I do not wish to deny there are cases of muscular asthenopia, only I have never happened to see many of them in my own experience.

If we seek for other disturbances in the system which may provoke asthenopia I know of two organs which play a considerable role in its production. These are the mucous membrane of the upper respiratory organs and the stomach. Various German rhinologists (Gruenwald) have referred to the existence of asthenopia in connection with suppuration of the different accessory sinuses. Some of these observations are suggestive rather than convincing. Personally, I have not had any definite experience in this connection. The cases of suppuration of the accessory sinuses seen by me which had ocular symptoms, were more in the nature of a steady discomfort than a distinct asthenopic complaint. I have, however, seen quite a number of instances, and my records place them at about 3 per cent. of all my observations upon asthenopia in which the nose played a greater or lesser role in the production of ordinary asthenopic symptoms. Most of the cases were of the nature of a chronic catarrhal rhinitis, with secondary hypertrophies, or, with stenosis due to deviations of or excrescences upon the septum. In placing the figure at 3 per cent. I must admit that it is not based entirely upon my therapeutic records. Not all of my patients were willing to undergo the tedious treatment that nasal stenosis would require, while others were not observed long enough. But in accepting that figure for my statistics I did so on the basis of the therapeutic successes in a smaller number of cases in which the probability of relationship was raised to certainty by the results of the treatment. At any rate, $I$. can refer to a reasonable number of instances where there was heaviness and discomfort in the eyes, burning or a dull feeling upon using the eyes, and where the removal of the spurs from the septum or the evulsion of mucous membrane of the turbinals led to permanent cessation of the symptoms. In some cases glasses had been prescribed either by myself or others. But in the convincing observations these glasses which had only been of moderate benefit could be discarded after the nasal treatment. In none did the glasses give entire satisfaction before the nasal treatment.

Another naso-pharyngeal condition to which I would attribute an occasional influence in the production of asthenopia is enlargement of the pharyngeal tonsil, the condition usually termed adenoid vegetations. I have seen at least twelve to fifteen cases in which children complained of decided asthenopia, where they could not use the eyes without discomfort, and where glasses given by myself or others did not prove wholly satisfactory, although the correction of the ametropia was not entirely useless. In these cases the removal of the adenoids gave definite results, namely, complete relief from the previous asthenopic symptoms. In all these instances, however, we can not exclude more or less instability of the nervous system. Indeed, I am not ready to admit that $e x a g-$ gerated asthenopia of any kind, or from any cause, can occur in a person whose nervous system is perfectly up to par. There are all possible degrees between normal asthenopia and the exaggerated form, because under the present conditions of our civiliza- 
tion there are only relatively few persons whose nervous system is trained from youth and reared by proper inheritance to the strictly normal physiologic condition.

As regards the influence of the stomach upon asthenopia I can not quote any statistics. My records are not detailed enough in all instances. Moreover, I am not sure that stomach disturbances alone would ever account entirely for asthenopic complaints. But I have observed quite a fair number of instances in which asthenopia associated with refractive errors, or without any measurable error of refraction, could not be relieved by any means whatsoever until the patient's stomach was cured of the condition in which had been, presumably a chronic gastritis. These individuals showed a coated or furred tongue, complained decidedly of distress of the stomach, had gaseous eructations, bloating, or general discomfort after meals, or, at least, after any indiscretion of diet. It is in these cases, as a rule, that we can not get relief until we place the patient upon rational diet, and prescribe sufficient outdoor exercise. On the other hand, by advising such measures a fair number of dyspeptics can get rid entirely of their asthenopic symptoms and may be able to dispense with glasses, which previously had been a necessity, although without ever having obtained full satisfaction from the glasses alone. This perhaps is as much as I can say definitely upon the subject of asthenopia not dependent upon refractive errors from the basis of my own experience.

Unfortunately, our therapeutic influence upon the nervous system which is at fault in such cases, is at the best a slow and often imperfect one. We can not correct hereditary influences. The patients are not always able to change their faulty babits. The pernicious after-effects of infectious diseases, like typhoid fever or measles, as a rule, are not amenable to treatment, only to time. But the condition of anemia which underlies this trouble can quite often be benefited by the administration of iron, and iron is a valuable adjuvant in the treatment of asthenopia if anemia be present at the time.

I might add a few words about the relation of some of the vague forms of asthenopia to hysteria. I was led to these views by observing the relatively acute onset of asthenopia in some instances. We all know that, as a rule, asthenopic patients can not state exactly when their annoyance began. In a small minority of instances, however, a time can be fixed and it coincides with some pernicious influence active at the time, for instance, the sickness of a child necessitating long waking hours of the mother, or overwork in the preparation for examination by students. Again, in other cases a change of boarding house with poor diet may have led to dyspepsia, while in a few of my observations the occurrence of acute coryza preceded the ocular disturbance. In such cases of asthenopia not dependent upon refractive anomalies with relatively acute onset I have had good results, provided they had not lasted long, by removing these pernicious factors, insisting upon proper hygiene, proper muscular exercise and absolute rest, if possible, for the eyes. By strictly carrying out this treatment many of these patients were cured within a number of weeks. On the other hand, if we get these cases after they have persisted for months, if they have been insufficiently treated, or have not sought medical advice at the proper time, we all know how very persistent such asthenopic complaints may be, even though the original cause has ceased to act. The persistence of the asthenopia when the starting cause is a matter of the past, might be logically attributed to hysteria. After all, perhaps, as good a definition as we can give of hysteria is "functional neuroses which are dependent upon psychic influence." Asthenopia in the cases mentioned does not start from cerebral influence in the first place. It may start from some tangible cause as coryza, dyspepsia, persistent overwork, etc. After these causes have ceased to act, the persistence of asthenopia in some cases is purely psychical. At least, we can find in some instances no somatic anomaly whatsoever which would account for the persistent asthenopic annoyance, and close analysis renders it probable that the patient retains the remembrance of his former suffering and suffers still when using his eyes, simply because he expects the discomfort.

About the only mode of therapeutic influence which I have found of benefit in these cases was to get the patient to forget the trouble gradually. If circumstances permitted I advised to drop work entirely. It is by change of surroundings in these slow cases, especially by a vacation and traveling; it is by oblivion of the annoyance attending previous eye work and by the suggestive influence of promised relief that $I$ have attained moderately satisfactory results in these cases where no somatic condition remained to which the asthenopia could be attributed.

DISCUSSION.

Dr. CASEY A. Wood-There are two causes of asthenopia, unconnected with the refractive state, that are common enough and to which I would draw the attention of the Society. First of all are those minute choroidal changes which one, now and then, observes about the macular region. In Moorfield's we were accustomed to give certain phases of these the name of .Tay's choroiditis. They occur, in my experience, mostly in young adults, and although they are confined entirely to the choroid, I have a suspicion that in many instances (and I believe that I have been able to show it) that there is a slight lowering of central vision, which corresponds to ill defined relative scotomata. Exactly what these changes are and what they are due to I do not know, but I am certain that in many instances they produce asthenopic symptoms, because after correcting all refractive errors and after disposing of the various muscular anomalies that commonly produce eye strain no relief is obtained.

The treatment of such cases has with me been extremely unsatisfactory. I have never succeeded in doing very much for these patients except to give them temporary relief under atropin for long periods and to prescribe tinted lenses. After the effects of the atropin had worn off I endeavored to keep them from tiring their eyes, especially by prohibiting all near work. I recall very distinctly a case which I had that had been examined and treated by quite a number of ophthalmologists, by most of whom these changes had been recognized. After this patient had been under my care for months, during which time I treated her secundum artem, I urged her to take about two years' holidays from the work she was trying to do, but at the end of that time I do not think she was able to do more than a quarter or a half hour's near work at a time. In other words, I have come to regard such cases as practically incurable, at least while the choroidal process is active. Central vision was excellent in this case, $i$. e., distant vision was almost normal and very fine print could be made out.

A careful examination with the perimeter shows, in most instances, doubtful central scotomata for red and green, not 
always confined to the fixation point, but sometimes a little to one side of it, and not so well defined as one sees in toxic amblyopia and in similar diseases.

I hesitate to speak about the other source of asthenopia, although $I$ have referred to it in print before, because it is usually only a manifestation of the so-called neurasthenia. I refer to insomnia. In a scientific society like this it is hardly fair to speak of a mere symptom as productive of asthenopic symptoms, but, be that as it may, I think I am correct in asserting that in the presence of decided insomnia, not asso. ciated with organic disease, but which seems to be a part of a general neurosis, the treatment of cases of asthenopia is far from satisfactory. The correction of the refractive error, looking after the eye muscles, etc., do not produce the usual results. Whatever be the cause of the insomnia, I consider it my duty to tell the patient that unless it can be relieved in some way or other I shall not be able to do very much for him or her, as the case may be.

Dr. F. C. Нотz I shall speak of only those local conditions which produce asthenopia, and among these I wish again to refer to what Dr. Gradle has already touched upon, to blepharitis as one of the common sources of asthenopic symptoms not referable to refractive errors, and I lay more stress on this condition than did Dr. Gradle, and I do not agree with him that in those cases where there is a slight or hardly perceptible blepharitis, the inflammation produces asthenopia only because the patient is in an abnormal nervous condition; for I find whether the blepharitis is slight or well marked the eyes show a particularly marked sensitiveness to any irritating cause, such as exposure to light, to wind, and consequently the exertion of the eyes in near work produces congestive conditions in the lids, and the result is a feeling of heaviness due to the congestion, and expressed by the patient as fatigue, burning, smarting and pain leading to headaches.

We know that some time ago errors of refraction were charged as causing blepharitis, and it has become a habit with many oculists to prescribe glasses and nothing else in cases of blepharitis. I still insist that the relief is more prompt by paying attention to the local treatment of the inflammatory condition of the lid than to the refraction, and I know many cases in which glasses have been worn for years and no relief of the asthenopia was obtained, when under proper local treatment the patient was relieved and could use his eyes with perfect comfort, whether he had the glasses on or off.

We find a similar condition in the conjunctiva. Very often the inflammation is so slight that it is not shown over the tarsal portion of the conjunctiva, which on eversion of the lid looks perfectly well. There is of ten only a slight congestion of the retro-tarsal folds, a congestion which is aggravated by near work and leads to a succulent condition of the retro tarsal folds, which causes a feeling of fatigue to the patient. These slightly succulent or congested folds are usually not exposed when we turn the lid in the ordinary way, but they can be very easily brought into view when the eyeball is pushed back into the orbit by slipping the lower lid over it and pressing upon the lower lid, pushing it back into the socket, while the everted upper lid is held against the supra-orbital margin. This makes the retro-tarsal fold spring forward and in many cases where the conjunctiva looks perfectly normal when the lid is everted in the usual way, you will be surprised to find a diseased condition of the fold which fully accounts for the complaints of the patient.

A third local condition has also been touched upon, viz., slight changes in the choroid. I would mention as quite frequent an excessively saturated redness of the fundus, a slight indistinctness, or blurring of the outlines of the papilla, and changes in the pigmentation. Very minute white dots scat. tered over the fundus have also been observed by me and I had reasonable grounds to regard them as the local condition for the asthenopic complaints. In some of these cases I discovered little choroidal patches in the periphery of the fundus, so that I am inclined to think that in many cases which are considered as choroidal hyperemia there is an actual peripheric choroiditis which under the strain of near work produces painful eyes and the symptoms of asthenopia. Old people during the development of cataract of ten complain of a dull recurring pain in the eye, and Dr. Risley has called our attention to the fact that in a good many of these eyes there are changes in the periphery of the choroid.

Dr. Chas. M. Robertson, Davenport, Iowa-Notas much has been said about the nasal causes as I think there should be. Dr. Gradle hinted at the subject in saying that stenosis of the nasal cavity might be the cause, either from enchondroses, an excrescence, a deviated septum, or from chronic rhinitis. The only form of rhinitis that is exempt, according to American authorities, is the atrophic, although Schwartze, and some others than he in Europe, state that they have seen cases originating in atrophic rhinitis. My experience has taught me that we are more liable to have reflexes from vaso-motor paresis than from chronic rhinitis and true hypertrophic rhinitis, although the great majority of cases of hypertrophic rhinitis are the result of a paretic condition. Some authors believe that an enchondrosis on the septum acts by producing a vasomotor paresis behind the occlusion thus formed and not from the enchondrosis per se. A spur may act primarily by producing pressure irritation to the turbinated body opposite.

I have had several cases in which the removal of the spur was followed by complete relief. A great many cases of conjunctival irritation or blepharitis may be due to obstruction by pressure of the inferior turbinated body on the lachrymal duct opening. I have had one case of such where cauterization of the inferior turbinate relieved the condition which produced the asthenopic symptoms.

Dr. W. F. CoLEman-We all recognize the fact that probably 90 per cent. of all cases of asthenopia are due to refractive errors. Of the remaining 10 per cent. I agree with Dr. Gradle that perhaps only 3 to 5 per cent. are due to muscular condition; not that muscular insufficiencies are uncommon, because in non-asthenopic eyes they are extremely common, but that relieving these muscular conditions does not cure the symptoms in an asthenopic patient. Tenotomies in my limited experience have not been successful. Of those having satisfactory results the ones dealing with vertical insufficiencies have been most satisfactory.

Dr. Coleman then reported several cases showing that in spite of every effort to correct refraction and muscular insufficiency the symptoms remained.

Dr. WM. H. WiLder-Dr. Gradle has covered the subject very thoroughly. I would like to speak particularly of the peculiar "pepper and salt" appearance of the retina. In Moorfield's it was Mr. Nettleshıp's habit to call attention to this condition, especially in young adults and children. It may be that this peculiar arrangement of the pigment epithelium is sufficient to cause hypersensitiveness of the part.

Dr. Hugh T. PATRICK-There were one or two points brought out in the discussion that I might speak of. Dr. Wood spoke of asthenopia due to insomnia, and I wish most emphatically to dissent from any such way of stating the interrelation of symptoms. Insomnia is simply a symptom of disease, and I do not believe that any case of asthenopia can be cured by treating the insomnia per se, because it must in the nature of things be treated by treating the underlying nervous or other conditions. Mans of these cases of asthenopia are nothing but excessively nervous subjects. It is to be expected that a person who is nervously exhausted, who is in the true sense of the word a neurasthenic, who is suffering from nervous prostration, should suffer from asthenopia. He gets tired if he walks too far, and gets tired if he follows a train of thought. Such a person 
would not be expected to read as he ordinarily does. We should expect him to become weary and the print to blur.

There is another class of neurasthenics that suffer from astbenopia, and they are the neurotics par excellence; the patients who show the classical symptoms of neurasthenia from insufficient cause. Such is the laborer who, after overlifting, shows the typical symptoms of neurasthenia coming on one by one, and with them asthenopia. Or a woman who undergoes a trivial gynecologic operation, where there is no material loss of blood, no shock, no infection, but anxiety, apprehension, or other abnormal psychic condition, and who after the operation develops one after another, generally slowly, the typical symptoms of neurasthenia and asthenopia. The asthenopia of these cases arises not from overwork and nervous strain, but from psychic causes. To treat such cases by treating any anomaly of the eye alone is very short-sighted. It would also be shortsighted to treat only the nervous system without treating the ocular abnormality. In may of these cases the ocular symptoms may be the most pronounced, and so largely mask the other manifestations.

I wish to impress from the standpoint of the neurologist, that in these cases neither rest, over-feeding, or anything but psychic treatment will do any good, if any good can be done.

Dr. C. W. HAwLEY--I would like to state that I find more and more the influence of general conditions on asthenopic patients. I no longer confine myself in many cases to the exclusive treatment of the eyes, but often have cause to congratulate myself for treating general conditions, and in this way relieving the asthenopia.

\section{SURGERY ONE HUNDRED YEARS AGO. AN HISTORICAL STUDY}

BY DR. GEORGE FISCHER.

DEDICATED TO THE GERMAN SURGICAL ASSOCIATION.

TRANSLATED FOR THE JOURNAL OF THE AMERICAN MEDICAL ASBOCIATION BY CARL H. VON KLEIN, A.M., M.D.

(Continued from page 413.)

CHAPTER II.-THE QUACK.

Family quackery, old women, shepherds and others; The charlatan at the annual fair; Secret remedies; Hernia curers, castrators; Cataract-couchers, Hilmer, John Taylor; Stone cutters; Frère Jacques, Rau ; Hangmen, torture, guillotine; Quacks in foreign lands; Remedy against quackery ; Our time.

Quackery is an evil innate in human nature, and enters the sick room with every old woman. Who is there that visits a patient and does not feel impelled to pass judgment on his ailment, to display wisdom as to diet and temperature, or to recommend with the utmost eloquence a remedy which has at some time helped this and that acquaintance? With this misguided condolence, which is not peculiar to the feminine sex, there sometimes lies behind the impulse to play the doctor, only indiscrete sympathy, but very often it is largely arrogance and self-conceit. The traditional blundering of mothers and aunts, even to this day, makes the life of the practising physician so bitter that he often leaves the sick room feeling that medicine is indeed a sublime science but a miserable bus. iness. This well meant quackery is only a little twig of that rankly luxuriant quackery of the 18th century. which like a poisonous vine shot up out of the superstition and prejudice of the German people. However much custom, habits, laws and forms might change. the prejudices as to medicine remained fixed as they had been for centuries and were handed down from one generation to another. The stupidity of the public promised rich plunder.

The people were wholly ignorant in medical matters. They had no opportunity to instruct themselves concerning life and health, and were incapable of distinguishing the true physician from the quack. Of public hygiene, the physicians themselves knew little and whenever they ventured to interfere were strenuously opposed by the lawyers, who had always claimed for themselves the management of state affairs. Various causes contributed to lead the public into the hands of the quack. The large number of ignorant physicians and surgeons, who belonged in the same class with the charlatan and decried scientific training as useless; their wrangling, the trivial character of the doctor's examinations, all undermined confidence in the medical profession. Other people, especially the clergy and the apothecaries, were very ready to grasp them by the hand. A man who every year prepared so many prescriptions for every possible ailment must necessarily become so wise as to be able to cure those ailments: no one for a moment doubted his skill, so they asked his advice and freely took his medicines. This class embraced, besides the barbers, bathkeepers and midwives, other wise people, apothecaries and old women, root-gatherers and alchemists, shepherds and blacksmiths, hunters, hangmen and other riff-raff (Lumpenpack), The army of pretenders was countless. They all enjoyed unquestioned confidence and, as the rabble believed, possessed a supernatural gift of healing. The peasant found conversation with a shepherd far more to his taste and to him more intelligible than with a physician. He feared he might not be treated with proper care by the physician, and moreover that he would be obliged to pay more for it. Furthermore there prevailed among the peasantry the idea that their diseases formed a distinct class which the physicians of the rich did not sufficiently under. stand. But quackery was also to be found in the better classes, among people of rank and education. With them blind faith had its roots in the taste for everything new and extraordinary, which indeed so despotically rules many people. They reproached the physicians because they uniformly clung to the old ideas and never sought out anything new. They vested great confidence in those who agreed with their own preconceived opinions, and ignored those whose treatment was in the least disagreeable. Human life was intrusted to the quack, but in all other things he was considered rude and ignorant. On the one side was the desire to become healthy, on the other the eagerness to make money; both of these conspired to unsettle the reason of the sick. People were imposed upon by anything and put faith in the most shameless promises, until at last the empty purse and disillusionment brought the victim to his senses. That the charlatan knew better how to gain confidence and was much oftener consulted than the scientifically trained physician, is a fact just as true today as it was one, two, or three centuries ago. In the sixteenth century all Europe swarmed with quacks, whose name (Quacksalber) arose at this time, when syphilis raged frightfully, and the medical pretender made an unwise and excessive use of mercury (Quecksilber). Bacon wrote of that time: "The rabble had in all times considered every old woman and every charlatan as a natural rival of the best physician and worthy to contest with him the preference at the sick-bed." In the seventeenth century the clamor over this nuisance was still unabated, and what Primrose then said of England might be written of Germany a hundred years later: "It is surprising that most people are so careful in the choice of their physician, that if a physician settles in 